\title{
ON THE CONSTRUCTION OF DRAWING ROLLERS FOR SPINNING MACHINERY.
}

\author{
BY Mr. WILLIAM WEILD, of MANChester.
}

The process of laying fibres of cotton, wool, and flax in parallel and continuous juxtaposition, for the purpose of being spun into threads for various manufactures, was performed until little more than a century ago by the workman's fingers, assisted sometimes by a preliminary operation of carding, which formed the short fibres into a soft fleecy roll of about $\frac{3}{4}$ inch diameter and 10 or 12 inches length according to the size of the card used. The spinning was done by the distaff, a wooden rod, round the top of which a bundle or fleece of the fibre intended to be spun was loosely wrapped. The spinner holds the distaff in the left hand, and the right hand is held about two inches below it, more or less according to the length of the fibre. A continuous lock of fibres is drawn out from the fleece on the distaff by the right hand, and the length between the two hands is twisted into a fine thread by the hanging spindle or bobbin, which is kept constantly revolving by the impulse of the fingers. The thread spun is wound up at intervals on the spindle by stopping the operation of twisting, and winding on to the spindle the length of thread already twisted: and to prevent the spun thread unwinding from the spindle whilst the next length is being twisted, it is hooked through a nick at the end of the spindle.

In $1733 \mathrm{Mr}$. Wyatt of Lichfield invented a machine for spinning cotton, by which for the first time a continuous thread was spun without the intervention of the fingers; and two factories were built and furnished with his machines, one at Birmingham and the other at Northampton. The cotton was first carded by hand and then passed between two cylinders which delivered the thread on to the bobbin while in the act of twisting. Both these undertakings friled; the 
machines have long since perished and no model or detailed description of them remains. About five years later Louis Paul of Birmingham along with Mr. Wyatt proposed to spin wool and cotton by a succession of rollers, cylinders or cones, each moving proportionately faster than the preceding, to draw down the thread or sliver to any degree of fineness that might be required. The writer believes he never used such an arrangement, but simply a series of pairs of delivery rollers set in a circular form but withont any drawing process. In 1742 a mill was erected in Birmingham where some of Paul's machines were set to work, driven by two asses working in a gin. $\mathrm{He}$ experimented for twenty years along with Mr. Wyatt, but nothing of any commercial importance ever resulted from their labours.

About 1765 two persons named Highs and Key experimented upon rollers for drawing the fibres into a continuous thread. There is no doubt but that Arkwright got some very valuable lints from them to enable him to develop the factory system. Whether Arkwright invented the drawing rollers or not, it was left for him to solve the problem how to construct a spinning machine with rollers arranged so that the first pair should draw and supply continuonsly a uniform sliver of parallel fibres in small portions, while a second pair should take hold of this and gradually draw out the filaments alongside of one another, and a third pair should draw the filaments ont still further to the proper extent for being twisted into thread. The twisting he performed with a spindle and a fly, and the machine also wound up the thread on to a bobbin as fast as it was spun. The writer believes that Arkwright was the first to make a practical machine combining all these processes, thongh the question of the original invention of the drawing rollers is involved in doubt.

For the purpose of "ginning" the cotton, or separating the cotton fibres from the seed, the "roller gins" as they are called are of the most primitive construction, simply and ingeniously made, and are of Indian origin. Fig. 1, Plate 13, shows a section of a roller gin of modern construction, drawn half full size. It is formed of two small rollers about $\frac{3}{4}$ inch diameter and from 6 to 9 inches long, made to revolve in opposite directions, as shown by the arrows, by means of 
toothed wheels. The bottom roller turns on fixed bearings, and the upper roller is kept in close contact with it by means of a lever and serew. The cotton seeds are fed forwards between the rollers from the table in front, a space being left between the edge of the table and the bottom roller to allow the seeds to drop down as they become cleaned of the cotton fibres by the revolving action of the rollers. A brush is fixed underneath the bottom roller to brush off any cotton fibres adhering to its surface. It is necessary that gins acting in this way should have rollers of small diameter, say from $\frac{5}{8}$ to $\frac{3}{4}$ inch, because the smaller the rollers, the more obtuse is the angle they present to the seed which is being cleaned, and the seeds are thereby better prevented from being drawn in between the rollers and crushed and mixed up with the cotton fibre. It is evident in referring to Fig. 2 that large rollers present an acuter angle to the seed, and with such rollers the seeds would unavoidably be drawn in and crushed and mixed with the fibre. The great object to be attained in ginning cotton is to get it free from all impurities; and it is found that the smaller the rollers and the slower their motion, the cleaner is the cotton fibre separated from the seeds : for if the rollers are above an inch in diameter and if they revolve very rapidly, they draw in soft, small, and false seeds, crushing them in their passage, and straining and otherwise injuring the cotton fibre.

The most improved gin of the roller class is shown in Fig. 3, Plate 13, drawn half full size, and is constructed with one large roller covered with leather and having small spiral grooves formed round it both right and left. A guard plate $\mathbf{A}$ is fixed near the surface of the roller, having a grating along its bottom edge just wide enough for the seeds to pass through to the roller; and between it and the roller a thin steel striker blade B vibrates a short distance up and down with a rapid motion. By this means the seeds are shaken and turned round in contact with the surface of the roller revolving in the direction of the arrow, and the cotton fibres are drawn between the blade $B$ and the roller, while the stripped seeds are rejected and drop down through the space between the blade $B$ and the edge of the feed table, having been thus cleaned of their fibres in a most thorough manner. 
In $1793 \mathrm{Mr}$. Whitney of America invented a machine known by the name of "Whitney's saw gin," which is shown in Fig. 4, Plate 13. It consists of a wooden cylinder with a series of circular saws $\mathrm{C}$, about 8 inches diameter, fixed upon it at regular distances. The edges of the saws project a short distance through a grid, the divisions of which are too narrow to permit the seeds to pass through. Care is taken that the saws revolve in the middle of the grid spaces, for if they rubbed against the bars they would tear the cotton filaments to pieces. A cylinder with brushes $D$, the tips of which touch the saw teeth, sweeps off the adhering cotton wool from the teeth of the saws by revolving in the opposite direction to the saw roller. The cotton seed as picked from the pods is thrown into the hopper $\mathrm{E}$, and the saws in turning round snatch the filaments from the seed which remains against the grid, and drag them inwards and upwards. The stripped seeds being too large to pass through the grid accumulate at the bottom of the hopper $\mathrm{E}$ and are let out at intervals.

The cotton after a further process of cleansing and carding is then ready to be operated upon by the drawing frame, shown in Fig. 5, Plate 14. Five or six cans F placed side by side contain each one sliver of cotton as delivered by the carding engine, and the several slivers are drawn together and combined into one by passing through the drawing rollers $G$, from which the combined sliver is conducted by the funnel and rollers $\mathrm{H}$ into the can $\mathrm{I}$ in front of the drawing frame. This process is repeated by combining five or six of the new slivers into another compound sliver by passing them a second time throngh drawing rollers; and for the manufacture of the finer descriptions of yarns this drawing process is repeated as many as half a dozen times.

In the construction of the drawing rollers G, Fig. 5, Plate 14, the lower roller, which is the only one driven, is of iron and fluted on the surface; the top roller, which has a soft yielding surface, is driven only by friction from the lower roller, upon which it is pressed by a weight $J$ suspended from a bearing in the centre of each roller, as shown half full size in Fig. 6 . The pair of rollers are shown in 
elevation, half full size, in Fig. 7, Plate 15, $\mathrm{K}$ being the centre bearing from which the weight is suspended; and the ends of the top roller are plain pivots LL working between vertical guides over the centre of the bottom roller, and free to move vertically, as seen in the transverse section, Fig. 6 .

In the first introduction of the new system of drawing cotton by rollers a great difficulty to be overcome consisted in the cotton lapping round the rollers during the drawing instead of being delivered clear of them; and there was also the difficulty of finding a material for the top rollers that should have an elastic surface and yet be durable and perfect in its action, imitating the delicacy of touch of the human fingers in the original distaff spinning, by giving constantly the exact amount of pressure required for drawing the fibre uniformly, so as not to over stretch the thread and thereby vary the thickness of any portion. Top and bottom cleaners M, Fig. 6, Plate 14, consisting of a rubber of flannel fixed on a board lying upon the top roller and held up under the bottom roller by a weight, were applied to prevent the cotton from lapping round the rollers; and previously it had been the practice for the attendant to rub the roller occasionally with chalk, which was the plan adopted by Arkwright and continued long after his time. The application of top and bottom cleaners has to a great extent remored that evil.

The construction of the rollers is a point of great importance, upon which the success or failure of the drawing process really depends. The ordinary top rollers are those made with an iron centre, painted with white lead and covered with thick felted flannel made for the purpose, over which is placed a cover of specially prepared leather. The importance of good top rollers in spinning cannot be over estimated; but as hitherto constructed in the manner just described they have several radical defects, which make it impossible to spin or draw cotton of uniform thickness or "counts." The top rollers are made in pairs with two roller surfaces or "bosses" as they are termed npon one spindle, and as ordinarily constructed these two bosses are solid upon the spindle. Practically it is impossible to get the two bosses of exactly the same diameter when clothed, owing to the rarying thickness of the leather. Then if one 
of them be 1-16th inch larger in diameter than the other when corered, the result will be a contention for speed between the two bosses ; for by the time one has made 20 revolutions the other wants to have gone 21. This causes slipping and abrasion of the surface of the leather, which causes the cotton to lap round the roller, and wastes the fibre of the cotton drawn, besides destroying the leather; and the roller also gives out irregular lengths of yarn or sliver. Again the ordinary roller requires oiling many times a day, owing to the bearings being all external and soon getting dry from the flakes or particles of cotton collecting about them and soon absorbing the oil; and in proportion as the bearings get dry the top roller drags and loses its speed, and the yarn or sliver becomes thicker. When oil is applied the roller goes freely for a time, giving out a greater length of sliver. By this frequent necessity for oiling not only is a great waste of oil occasioned, but the oil saturates and helps to destroy the cloth and leather covering of the roller, producing extra sticking and waste of the cotton.

Figs. 7 and 8, Plate 15, show half full size the most improved construction of these top rollers, the invention of $\mathrm{Mr}$. Evan Leigh of Manchester. $N N$ are the two bosses of the top roller, which are both loose upon the spindle, and $G \mathrm{G}$ is the corresponding bottom roller. The bosses of the top roller in this case revolve entirely upon the spindle, and the spindle remains stationary, instead of revolving within the hook that carries the weight and between the end guides as in the old plan. A section of one of the bosses of the top roller is shown in Fig. 7, showing the conical form of the end journals $L \mathrm{~L}$ of the spindle, which in conjunction with the coned holes at the ends of the rollers gives a capillary action always drawing the oil from the end bearings $L$ inwards into the parallel portion of the spindle inside the roller. The inner ends $O$ of the spindle are coned down in a similar manner, and the oil is thus prevented from escaping from either end of the rollers. The body of the rollers $\mathrm{N} \mathrm{N}$ is of cast iron, bored out with great accuracy and care, and is covered first with flannel and then with leather. The spindles are also of cast iron, and the weight for giving pressure to the top rollers is suspended from the centre $K$ between the two bosses. Each boss $N$ can now run at 
its own speed independent of the other, and thereby each delivers out correctly its proper length of sliver. The leather keeps smooth, and saves waste of cotton; and the bearings being internal and completely covered, the roller does not require oiling for weeks. These top rollers save the couplings of the lower rollers by taking less power to drive them, and avoiding the retarding action like that of a break, which was produced by the upper roller slipping over the fluted surface of the lower roller to the extent of the variation in diameter of the bosses on the upper roller. The spindle being made of cast iron as well as the roller, the tendency to wear is reduced to a minimum; for when two surfaces of cast iron have worked together a short time, the oil becomes absorbed in the pores of the metal, which attains a high polish, runs light, and becomes as hard and indestructible as glass. These top rollers run from one to six months without lubrication, according to the quality of oil used.

Another difficulty that spinners have had to contend with is the fluting or cutting up of the leather surface of the top roller by the action of the flutes in the bottom roller. When this occurs the fibres of the cotton get crimped and cut or broken in the act of being drawn, by passing between the two corrugated surfaces, and a greater length of thread is delivered than when the top roller is kept perfectly smooth: but the spinning of good yarns depends upon the regularity of all the threads as to quantity of fibre and length delivered. The bottom rollers were formerly fluted by longitudinal grooves cut with a tool at equal pitch all round the roller, and the impression left upon the top roller was consequently of uniform pitch, and continued deepening by the pressure of the corrugations always coming upon the same parts.

About twenty-five years ago a simple method of fluting the bottom rollers irregularly was introduced with a view to remove or correct the fluting of the leather rollers; this plan is illustrated in Figs. 9 and 10, Plate 15. The ordinary roller fluting machine may be said to be an ordinary planing machine with the addition of a ratchet motion to turn the roller from one flute to the next after each cut. The method of fluting the rollers with irregular flutes was as follows. A disc P 
was keyed upon the end of the roller $G$, on which a ratchet plate $R$ was placed eccentric to the centre $S$ of the roller and disc $P$. The click $\mathrm{T}$ of the ratchet moved the ratchet one tooth round after every cut of the tool $U$, and thus the flutes nearest to the centre of the eccentric ratchet $\mathbf{R}$ were closer together than those further removed from that centre, and therefore the more eccentric the ratchet the greater was the disproportion of the distances between the flutes. This is illustrated by the two segments shown by the dotted lines in Fig. 9, which at their outer extremities are the same width, namely the breadth of one tooth of the ratchet $R$; but where they intersect the circumference of the roller at $V$ and $X$, the distance of $V$ from the centre of the ratchet being double that of $X$, the breadth of the segment at that point and consequently the pitch of groove cut is also doubled. This arrangement to a certain extent obviated the tooth and tooth action which took place in the ordinary regular fluted rollers, the irregular pitch of the flutes in the new method causing their impressions upon the top roller to vary in position at each revolution; but it was not effective in saving the top roller unless there were considerable difference in the breadths of the flutes, which gave rise to another evil, namely irregular drawing of the cotton fibre : in fact in this plan a bad drawing roller was used to save the top roller.

The latest improvement in the fluting of spinning rollers was introduced by the writer about three years ago and is now being extensively adopted. Up to that time all rollers for drawing cotton and other fibres had been made with straight flutes parallel to the axis of the roller. The improvement now made in the fluting consists in forming the flutes spirally on the rollers, at an inclination of about 1 in 12 to the axis of the roller, as shown in Fig. 7, Plate 15, the grooving being done in the ordinary fluting machine with the simple addition of a twisting motion for the roller while in the act of cutting, similar to a rifling action in gun manufacture. By this means the upper roller rests upon several flutes at once, their number depending upon the length of each roller and the length of twist of the spiral flutes, instead of resting upon one straight flute as in the ordinary roller. In the ordinary roller, the flutes being parallel to the axis, 
the npper roller must make a slight ascent and descent in passing over the top and groove of each flute; while with the spiral flutes the top roller is uniformly supported and will not have the least rise and fall. A further improvement is made by inclining the flutes of one roller in the reverse direction to those of the next, as shown in Fig. 7 ; so that by turning end for end the top rollers, which are in short lengths, any tendency of the leather to flute may be corrected, since the flutes formed by one roller would be wholly or partly effaced by the reverse spiral of the flutes in the other roller.

All the forms of rollers that are grooved in a planing machine have a defect from the edges of the grooves being left keen with a slight burr upon them, which would cause the cotton fibre to adhere to the surface of the rollers. To prevent this a careful and tedious hand process has to be gone through with each roller, after cutting the flutes, in order thoroughly to smooth down the grooves by longitudinal rubbing with stone and emery; and the rollers are then polished by revolving in the same direction in which they are intended to run in working.

A very rapid method of manufacturing these spiral fluted rollers by means of a milling tool has been introduced by the writer, in which the whole process is completed at one operation, leaving the roller finished ready for putting to work without any intermediate preparation being required. The machine for this purpose is represented in the front elevation, Fig. 13, Plate 16, and the transverse sections, Figs. 14 and 15, Plate 17 ; and Figs. 16 and 17, Plate 18, are enlarged views showing the details of the milling process, drawn half full size. The roller A to be fluted is laid on friction rollers B B, Figs. 16 and 17, supported by adjustable stands upon a saddle $\mathrm{C} \mathrm{C}$ fixed on the main bed of the machine, Figs. 13 and 14. The milling tools D D, shown full size in Figs. 11 and 12, Plate 15, are steel discs about 2 inches diameter, and $\frac{3}{8}$ inch wide on the edge which has upon it a counterpart of the flutes to be impressed upon the roller. Each milling tool is carried by a cranked lever $\mathrm{E}$ working on a centre at E, Figs. 14 and 15, Plate 17, and acted on by the weight $F$, which exerts a downward pressure upon the milling tool of about $1200 \mathrm{lbs}$. , regulated by 
shifting the weight $\mathrm{F}$ to the extent required. The milling tools are thrown out of action by the eccentric shaft $G$ being turned half round, which depresses the tail end of each of the four levers $E$, lifting the weights $\mathbf{F}$, and raising the mills $\mathbf{D}$ from off the roller, as shown in Fig. 15, Plate 17. The mills are first placed about $\frac{1}{8}$ inch upon the ends of each roller to be cut, as shown dotted in Fig. 16, Plate 18; four roller bosses all on one solid spindle are milled at one and the same time. The roller to be milled is turned by the driving pulley $\mathrm{H}$, Fig. 13, Plate 16, through a universal joint $I$, in order to prevent any strain upon the roller during the process. The milling tools with their levers and weights are all carried by a sliding carriage $\mathbf{J} \mathbf{J}$, and traversed along the bed of the machine by a screw $K$ with a selfacting feed, as in an ordinary slide lathe. When the carriage $J$ has traversed the length of one of the bosses of the roller, the machine is stopped by the handle and strap rod $L_{1}$; and the mills are lifted up from off the roller by turning the eccentric $G$. The carriage $J$ is then moved forwards by the handle $\mathbf{M}$, on which is a pinion working into a wheel on the same shaft as the crown wheel $\mathrm{N}$ gearing into the traversing screw $K$. The four mills are thus brought into a position to start milling the four remaining bosses of the roller. The weights $\mathrm{F}$ are then let down, causing the mills to bear on the roller; and the crown wheel $\mathrm{N}$ being locked by the handle $\mathrm{O}$, the earriage $J$ will then traverse the mills over the bosses. The mills work at the rate of 60 revolutions for 1 inch of traverse, the roller revolving at the rate of about 120 revolutions per minute; and the mills being about double the diameter of the roller, the fluting advances about 1-120th inch in each revalution of the roller.

Rollers manufactured in this way by milling have a much harder surface and will consequently wear much longer than those fluted by the ordinary cutting system, the surface of the metal being condensed by the pressure in the milling process. Another advantage is that the grain of the iron is laid in the best direction for ensuring smoothness of action in the working of the roller, since the roller is driven in the milling process in the same direction in which it is intended to run in the drawing frame; and the mill leaves it sufficiently polished to be immediately used for drawing. 
The drawing rollers are from $1 \frac{1}{4}$ to $\frac{5}{8}$ inch diameter, and 16 to 22 inches length, with from two to eight bosses of proportionate length upon each; and the several rollers are coupled together by square spigot and socket joints formed on the ends of the rollers, as shown in Fig. 18, Plate 19, extending to a total length of 30 to 120 feet, all driven from one end. The manufacture of spinning rollers has of late years been much improved by the introduction of special selfacting tools for each operation. First, the bar of iron is cut up into lengths, which are then heated and rolled between three rollers to make them true and straight. Secondly, rough squares are forged at one end of each bar with a Ryder's hammer, to form the spigot. Thirdly, each bar is cut to the exact length required, and a hole is bored up longitudinally about 3 inches at the other end, as shown full size in Figs. 19 and 20, Plate 19, six rollers being bored at a time in a multiboring machine. Fourthly, the round holes thus bored are squared out for the coupling by means of three punches, as shown in Figs. 21, 22, and 24, each punch larger and shorter than the preceding, so as to allow room for the shavings to lie at the bottom of the hole, as seen in the longitudinal section, Fig. 23. The last punch, Fig. 24, does not entirely square the hole, leaving a space to allow the air to escape from behind the punch in order to prevent risk of bursting the socket; and thus a portion of the original circle is retained on each side of the square socket for centering the roller truly in the subsequent turning process. For squaring up the spigot end of each roller, Figs. 25 and 26, four or six of the rollers are put upon a machine with as many vertical tools, and two opposite sides of the square are cut at once by a pair of tools, the roller being carried by the centres at the ends so as to ensure the square being truly central with the roller. The roller is then turned one quarter round and the remaining two sides are cut in the same manner as the two former ones. The rollers are then fitted into one another, as shown in Fig. 18, and marked as they are intended to work in the spinning machine; and they are turned in pairs to ensure their running true. They are then ready for the fluting machine already described.

Figs. 27 and 28, Plate 20, show a set of drawing rollers drawn full size. $P$ and $R$ are the carrying rollers, in which the top rollers 
are sometimes made of iron, smooth or corrugated, and sometimes covered with leather, $\mathbf{P}$ being the back or feeding rollers; and $\mathbf{S}$ are the main drawing rollers, the upper one covered with leather, which run about seven times the surface speed of the first rollers P. In Fig. 27 the three pairs of rollers are placed close together for short fibred cotton, and Fig. 28 shows them further apart for long fibred cotton. As the different qualities of cotton vary in length of fibre from 5 to $1 \frac{1}{2}$ inch, the proper adjustment of the rollers is absolutely necessary for perfectly attenuating the mass of fibres passing through the drawing rollers. The distance from the centre of one pair of rollers to the centre of the next pair, or the "nip" of the rollers as it is called, should in no case be less than the greatest length of the cotton fibre, or else the fibres would get broken or pulled asunder by being still held by the back rollers when caught at the front end by the drawing rollers running at the higher speed. If on the other hand the successive pairs of rollers were too wide apart, the shorter fibres would not be taken hold of in a perfect manner, not being caught hold of by the quick rollers soon enough after being let go by the former rollers, thereby making a false or irregular thread.

A set of drawing rollers and a bundle of fibre is shown in Fig. 29, Plate 20, the rollers being drawn full size, with the actual distance between the successive pairs longitudinally, but with the vertical space between the two rollers in each pair exaggerated for the purpose of illnstrating the nature of the drawing action: PP are the back or feeding rollers, and SS the main drawing rollers. It is of the greatest importance for the production of good and regular yarn that the sliver of cotton fibre should be regular in thickness, and also fed in with a regular continuous motion. In order to illustrate the action more clearly, the fibres are represented in the diagram, Fig. 29, alternately white, shaded, and black; and the length of the fibre corresponds with the distance from centre to centre of the successive pairs of rollers. The number of fibres in the sliver entering the feed rollers PP is represented as 10 in the diagram; and the ratio of speed of the second pair of rollers $R R$ to that of the first pair being taken for the purpose of the diagram as 10 to 7 , the fibres get drawn out past one another until they represent 7 fibres in thickness under the second pair of 
rollers $\mathrm{R}$. The third pair or main drawing rollers SS run quicker than the second pair in the assumed proportion of 7 to 3 , and consequently the fibres passing through the third pair $S$ are represented by 3 in thickness of sliver. Thus the sliver or bundle of fibres in passing through the three sets of rollers would in this case be diminished in thickness in the proportion of 10 to 3 , and increased in length in the same proportion: so that the greater the difference of speed between each pair of rollers, the finer is the yarn produced. In practice the third or main drawing rollers $S$ run about seven times the surface speed of the first rollers $\mathbf{P}$, as previously stated; so that the sliver of fibres is reduced seven times in thickness of fibre, and increased seven times in length. It is said that the first inventors of the drawing rollers got their ideas from the action of rollers drawing or rolling iron; but it is evident that the drawing out of the fibres of iron for the purpose of elongating a dense mass of material is performed on a very different principle from the drawing action produced by a series of rollers running at different speeds on a large number of short loose fibres of fragile texture.

The spinning of short fibred cotton is practically limited by the smallest diameter that the drawing rollers can be made so as still to allow of constructing coupling sockets in the several lengths of the rollers, sufficiently strong to transmit the power required for a long length of rollers. The great bulk of the cotton machinery in this country is made for drawing cotton having a length of fibre or staple of 1 to 1 inch, comprising the better qualities of cotton, namely

\begin{tabular}{|c|c|c|c|c|}
\hline New Orleans & and & African cotton & to $1 \frac{1}{4}$ & get \\
\hline Brazil . & . & - & 1 to $1 \frac{1}{2}$ & $"$ \\
\hline Egyptian . & • & - & - 1 to $1 \frac{5}{8}$ & " \\
\hline Sea Island & 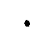 & . & $1 \frac{1}{2}$ to $2 \frac{1}{8}$ & " \\
\hline
\end{tabular}

as shown full size in the diagram, Fig. 30, Plate 20. But the cotton from the new sources of supply now being introduced has a much shorter length of fibre, namely

East Indian and Nankin cotton . . . to 1 inch length of fibre as shown in Fig. 30 ; and for the purpose of drawing this cotton it is requisite that the diameter of the rollers should not exceed 3 inch, in 
order to bring them close enough together to deal with $\frac{5}{8}$ inch fibre. The roller bearings are made to slide transversely, as shown in Fig. 6, Plate 14, so as to be accurately adjusted to the particular length of fibre in each sample of cotton to be drawn; and the rollers have to be small enough for the shortest fibre intended to be drawn.

Wrought iron is not satisfactorily applicable to rollers of so small a size as $\frac{3}{4}$ inch diameter when carried to a great length; for in addition to the weakness of the couplings the total amount of torsion in a long length of rollers causes the time of action to be sensibly different at the two extremities of the machine, so that the delivery is too slow in starting at the far end, thus giving an undue stretch upon the yarn and occasioning breakage at those parts. To obviate this difficulty a trial has recently been made by the author's suggestion of Bessemer steel instead of wrought iron as the material for the rollers, and this has been successfully adopted in some mills. Steel rollers have been formerly tried in a few cases, but the great expense prevented their adoption; whereas the moderate cost of the Bessemer steel admits of its use, whilst its fine homogeneous quality renders it specially suited for the purpose. A sample of these rollers is exhibited, together with working models of a box or set of drawing rollers, throstle rollers, and mule rollers.

Mr. WeILD exhibited a drawing frame in action containing a set of the spiral fluted rollers and the improved top rollers; with specimens of the fluted rollers in different stages of the manufacture, and of the Bessemer steel rollers, and the milling tools employed for milling the rollers; also a specimen of the roller gin for cleaning the cotton from the seed.

The Chairmas thought the plan now described of milling the drawing rollers by the pressure of a milling tool, instead of cutting each groove separately in a planing machine, was highly ingenious; 
and in combination with the spiral direction of the grooves must be most beneficial in preserving the leather surface of the top rollers from injury by indentation. The employment of Bessemer steel for the rollers appeared an improvement of special value at the present time, if it would enable the new short-staple Indian cotton to be drawn and manufactured with the same facility as the old American and other cotton of greater length of staple, by the adoption of drawing rollers of smaller diameter than those hitherto used. He enquired to what extent the small diameter rollers of Bessemer steel were now employed, and how long the spiral fluted rollers had been introduced.

Mr. Weind replied that a mill at Preston was the only one at present furnished with the small rollers of Bessemer steel; but the spiral fluted rollers grooved by the milling process had been introduced about $3 \frac{1}{2}$ years ago, and were now being employed in more than three hundred mills in Lancashire and Yorkshire. During the last twelve months great numbers of the old rollers had been replaced by the spiral milled rollers, the stoppage of the works for want of cotton affording a good opportunity for making the change.

The Chairmax enquired whether the smaller rollers could be applied with equal facility to the long fibred cotton, if the latter were again supplied in the same abundance as formerly.

Mr. WeILD thought there would be no difficulty in applying the small rollers to the long fibred cotton; it would only be necessary to move the successive pairs of rollers further apart, to correspond with the greater length of fibre, which was easily done, as the roller bearings were carried in slots so as to admit of any adjustment horizontally: and the difference in the degree of contact of the top leather roller upon a bottom roller of 1 inch diameter or upon a bottom roller of only $\frac{5}{8}$ or $\frac{3}{4}$ inch diameter was so slight that it was scarcely capable of producing any perceptible difference in the drawing of the cotton. The prejudice against using small diameter rollers was owing to the expense attending their introduction into the present drawing frames; because it was not merely that the large rollers were removed and replaced by the small ones, but for this purpose the whole of the roller stands had to be removed and replaced by others having the roller bearings closer together, in order to suit the smaller 
diameter of the rollers, which involved a very heavy expense. The change was now being made in another factory at Preston. He showed a specimen of a roller frame fitted with a set of the small rollers, the front and back pairs of rollers being $\frac{3}{4}$ inch diameter, and the middle pair $\frac{5}{8}$ inch diameter.

The Chatrman asked what was the speed at which the rollers could be grooved by the milling process, as compared with the old method of planing the grooves; and also how the mills were made.

Mr. WeILD replied that by the milling process a roller could now be completely grooved ready for use in less time than it took to fix the roller for cutting in the old planing machine and get the machine ready for work. It took about $1 \frac{1}{2}$ minutes to mill a roller of eight bosses, milling four at a time. For making the mills a master roller was first made of exactly the diameter of one of the bosses of the drawing rollers, which was fluted spirally in a planing machine with grooves of the exact depth and pitch required, and afterwards casehardened. The soft iron mills were then put in the milling machine, and were themselves milled by the hard master roller, and afterwards casehardened. The iron used for the mills was made from scrap consisting of "card teeth," the fine wire teeth of the carding machines: the mills were thus not steel, but iron casehardened, which was found more suitable, since the best steel was found to crack and fly under the heary pressure of milling. What was wanted was a hard and tough quality of metal, having a surface hard enough for indenting the rollers in milling, but not so brittle as to crack under the pressure; and these qualities were admirably combined in the casehardened iron made from the card teeth. It was now a regular trade in Manchester to make that iron from the card teeth to be used for the engraving rollers employed in calico printing; and for that purpose no kind of steel would do that had the least flaw in it. $\mathrm{He}$ showed specimens of the mills that had been in constant work for six months and were not worn out yet, exhibiting scarcely any signs of wear at present. He showed also a specimen of a roller milled to a much greater depth with two opposite spirals of rapid pitch, producing a deeply "pitted" or grated surface; such rollers were required for drawing off the cloth from looms, and were previously made by 
punching a piece of sheet iron in the manner of a grater, and wrapping it round a wooden roller with the rough side outwards.

The Chairman remarked that the homogeneous character of the Bessemer steel would be a great advantage in the mannfacture of the drawing rollers, and its superiority to ordinary steel in that respect was clearly seen in the two specimens of rollers now exhibited, one of the Bessemer steel and the other of ordinary steel, the latter having its surface full of minute lines while the former appeared perfectly homogeneous and free from even the faintest appearance of marks. In respect of strength, he had tested a great deal of the Bessemer steel, and found it had nearly double the tensile strength of the best wrought iron.

Mr. WEILD observed that the steel he had used for the small drawing rollers was not the best Bessemer steel, but was obtained at a cost of about $\mathfrak{E} 25$ per ton. It was completely homogeneous and free from cracks, and answered the purpose very well for the drawing rollers. It was not necessary to make the rollers of the very best Bessemer tool steel, because they had not to be tempered after the milling.

Mr. J. Fernie thought the new mode of fluting the rollers was a beautiful and ingenious application of the milling process and much superior to any plans of milling previously in use. He enquired whether any attempt had been made to apply the same method of milling for making rimers for rimering out circular holes.

Mr. D. Jor observed that the milling process had the effect of rounding the edges of the grooves instead of leaving them square and sharp as in the former planed grooves; but a rimering tool required square cutting edges, not rounded off, which could not he thought be obtained by milling.

Mr. WeILD said he had not tried the milling process for any other purpose than that described; and there was a sort of tooth and tooth action between the milling tool and the roller, whereby the edges of the grooves were necessarily rounded off, which was an advantage in the make of drawing rollers. The success of the operation depended on taking in very small portions of the surface successively to be acted upon by the mill : if it were attempted to mill one of the rollers by 
placing the whole of the inch edge of the mill upon the roller at once, it would be impossible to indent the surface ; but by beginning with a very small length of roller under the mill, and advancing the mill lengthwise on the roller only 1-120th inch in each revolution of the roller, the fluting was accomplished without any excessively severe pressure; and the remaining portion of the edge of the mill acted as a polisher following the milling, so that the flutes were milled and polished all at one operation. The result of using the milled rollers was that, in consequence of the roundness of the edges of the flutes and their spiral direction, the leather of the top rollers continued in good condition with a smooth surface for a much longer time; and this was a very important point, since a nice even yarn was obtained in spinning as long as the leather remained uninjured, but not after its surface became roughened by wear.

Mr. J. Fenne enquired how the rollers were got true in line and diameter, so as to run perfectly steady for such a long length as 130 feet, made up of so many short lengths jointed together.

Mr. WEILD explained that all the coupling sockets and spigots were cut by machinery, the rollers being accurately centred on the same centre holes in each operation, whereby perfect truth of work was obtained. The bar to form the roller, after being forged roughly at one end to the required square for the spigot, had a centre hole drilled at each end for centering it in the boring machine, where the socket hole was drilled and afterwards squared out to the exact size by three punches, working longitudinally and following one another in the hole: the roller was then centred by the same centres in an upright slotting machine for squaring the spigot end, and the two opposite sides of the square were cut simultaneously, after which the roller was turned one quarter round, and the two other sides cut in the same way. The rollers were then fitted together and marked, and afterwards turned in pairs in the lathe: Nos. 1 and 2 were first turned together; then No. 1 was removed, and No. 3 was turned with No. 2 ; then No. 2 was removed, and No. 4 turned with No. 3 ; and so on. By this means the whole length of a long line of rollers was made to run perfectly true. 
Mr. J. Farnie asked how the covering of the top rollers with leather was performed.

Mr. WeILD explained that the cast iron boss of the roller was first painted and covered with a layer of felted flannel; and then the leather was wrapped round outside by machinery, and a knife in the machine set at an inclination cut it off with a bevilled edge so as to lap accurately without increasing the thickness of leather at the joint: at the same time a glue brush was passed along the edge, sticking it down securely with strong glue. The top rollers were required to be both durable and elastic, and the leather formed a durable external covering, while the layer of flannel underneath gave the elasticity required to prevent the cotton fibres being injured in drawing.

Mr. D. K. ClaRK enquired what description of leather was used for covering the rollers; he understood that pigskin had been employed lately for the purpose.

Mr. WeILo believed the leather generally used for covering the rollers was common sheepskin, prepared slightly for that particular purpose.

The Chatrman proposed a vote of thanks to Mr. Weild for his paper and the numerous specimens he had exhibited, which was passed.

The following paper was then read:- 
COTTON DRAWING ROLLERS. Plate 13. Fig. 1. Roller Gin.
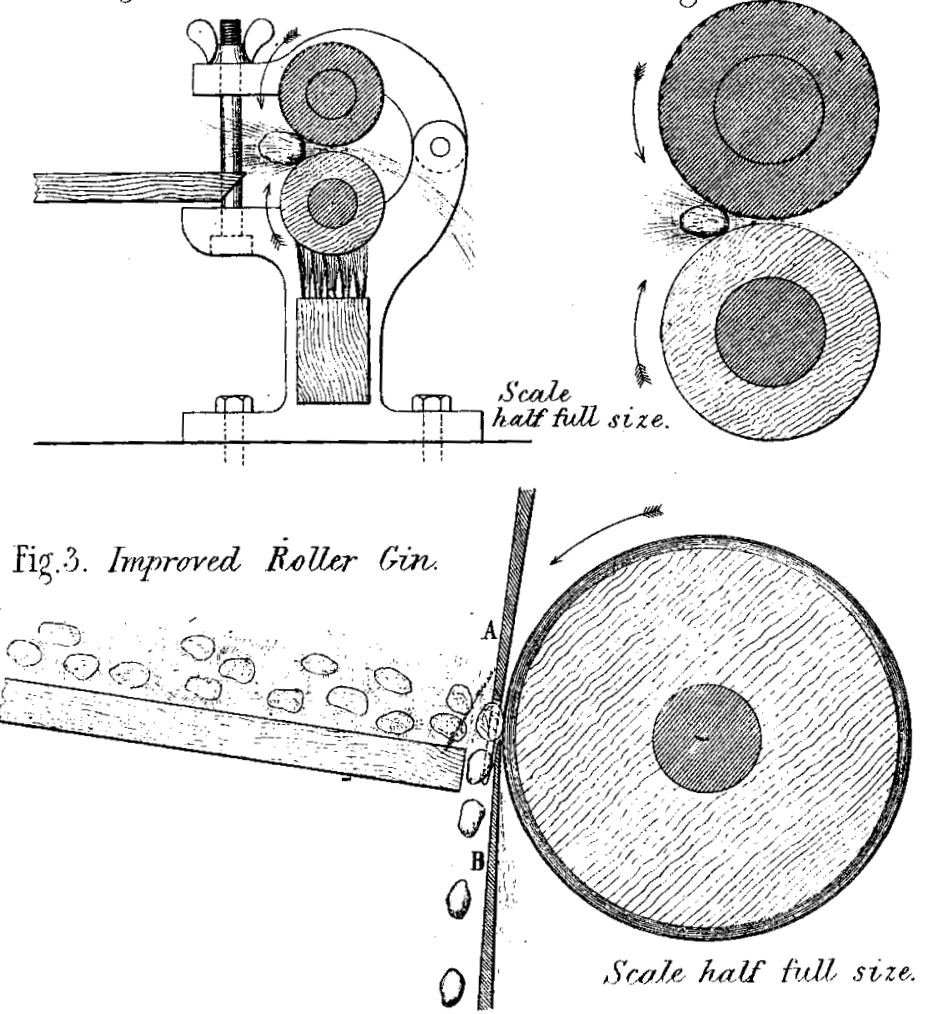

Fig. 4. Whilneys -Saw - Gin. 1793.

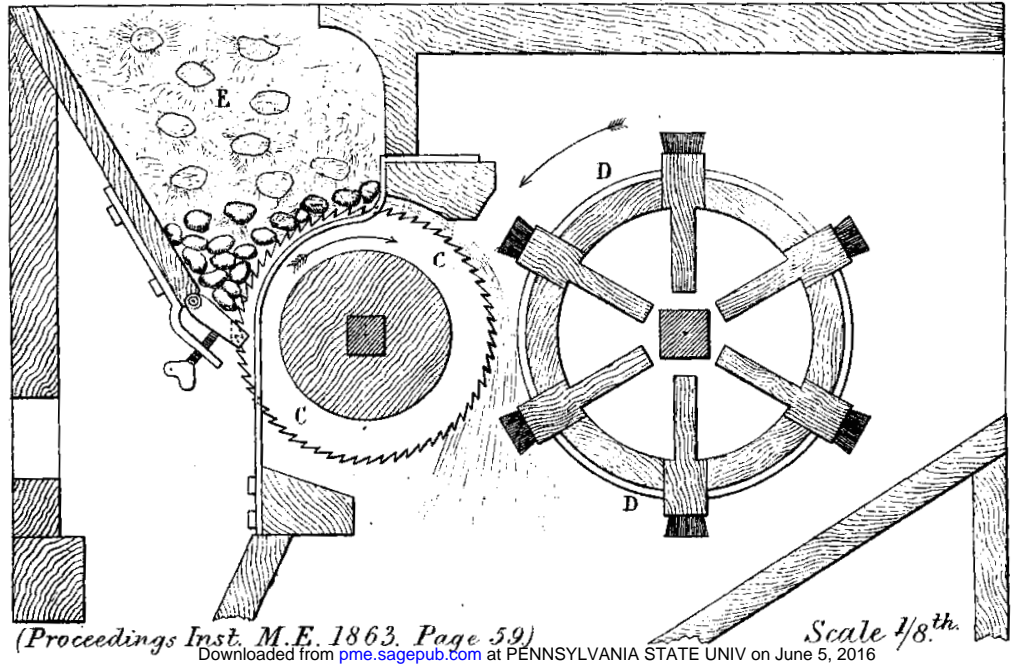




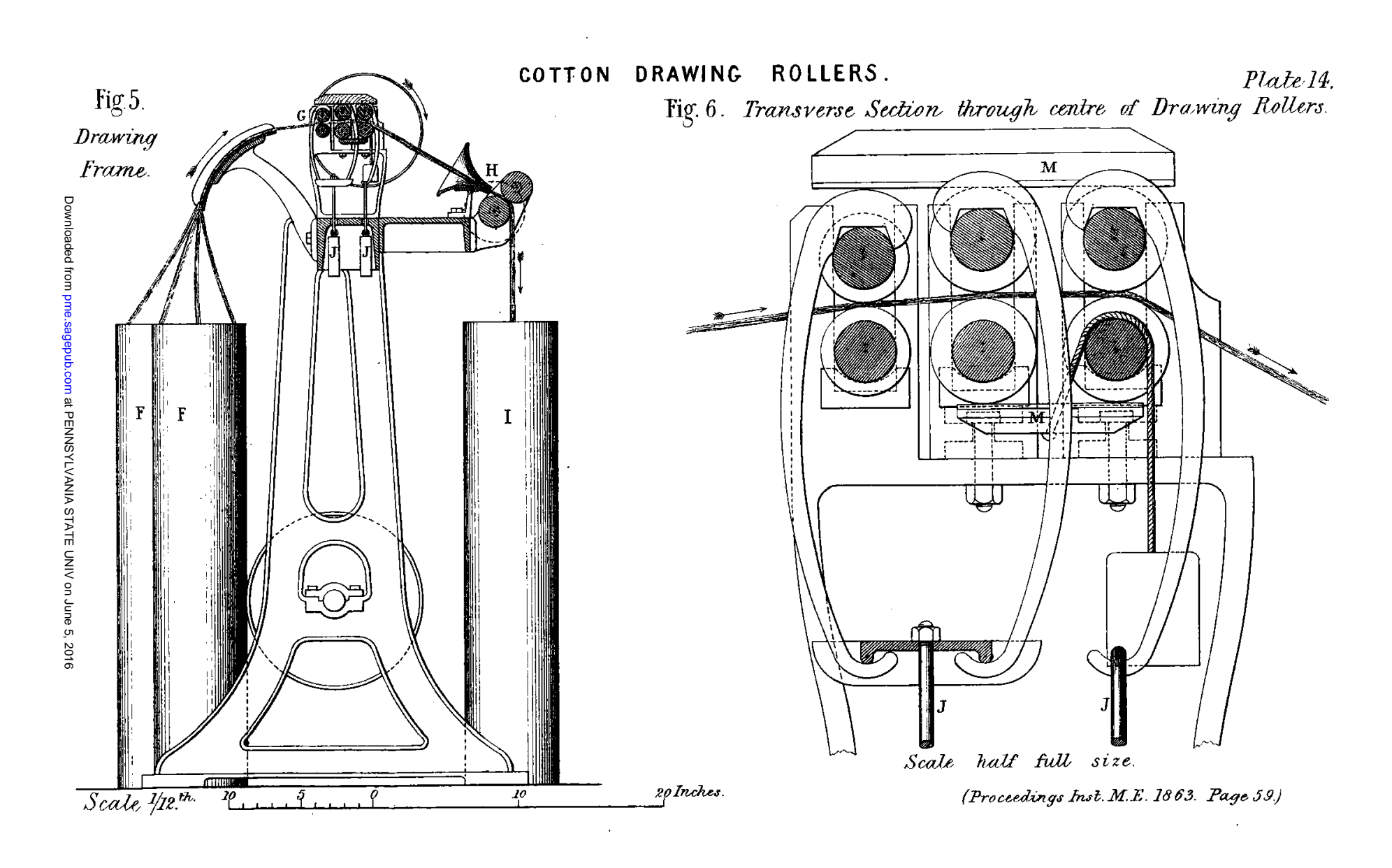


COTTON DRAWING ROLLERS.

Fig.7. Longitudinal View of improved Drawing Rollers.

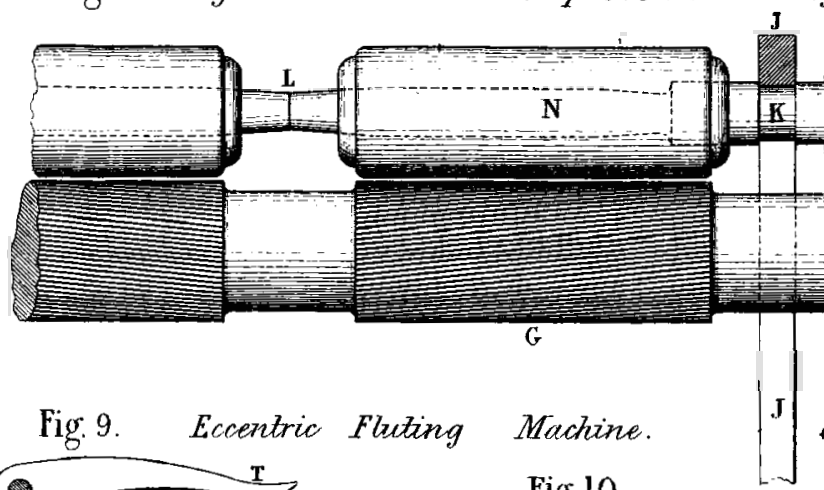

Scale half full size.

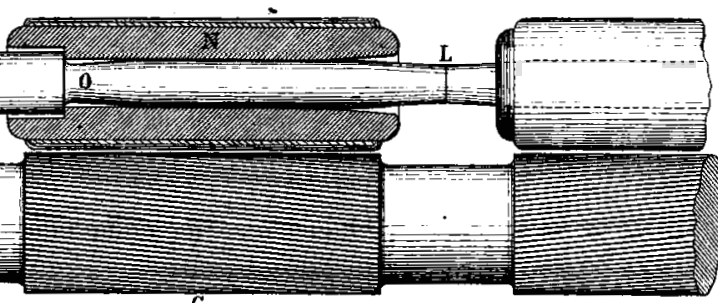

Plate 15 .

Fig. 8.

Transverse Section.

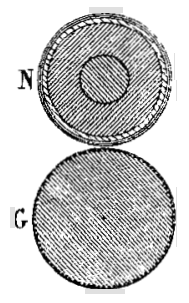

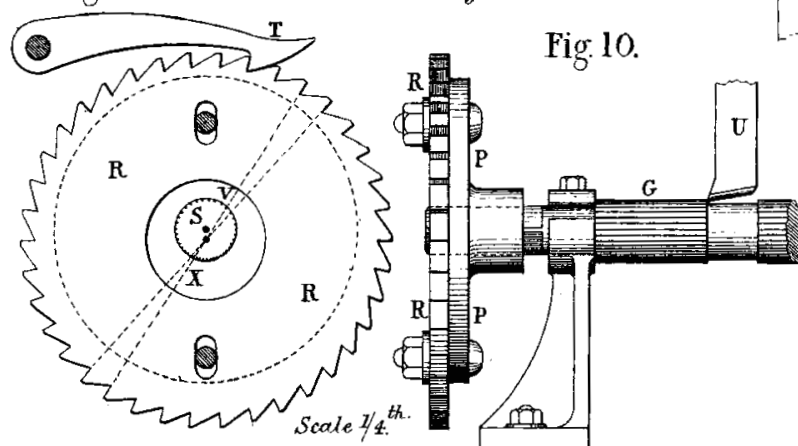

(Procuedings Inst. M.E.1863. Page 59.)

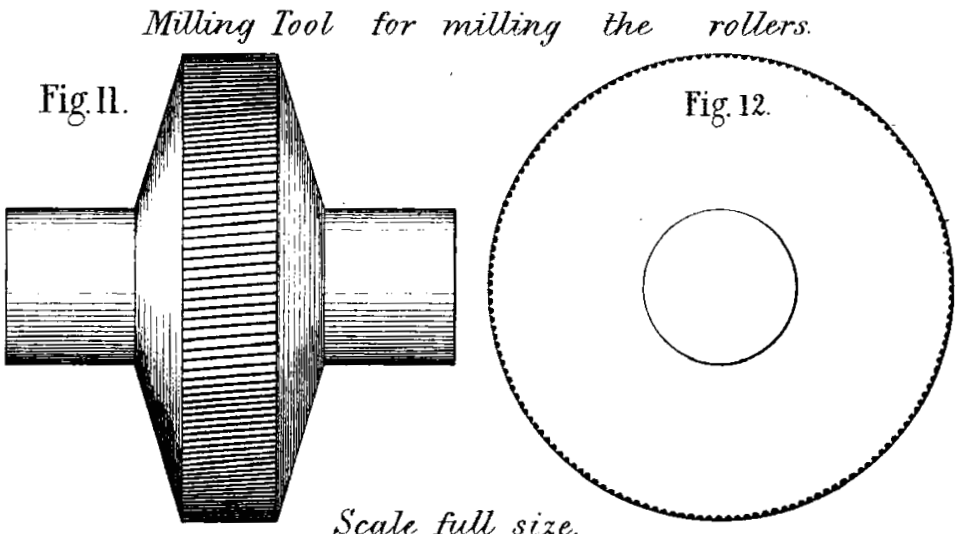


COTTON DRAWING ROLLERS.

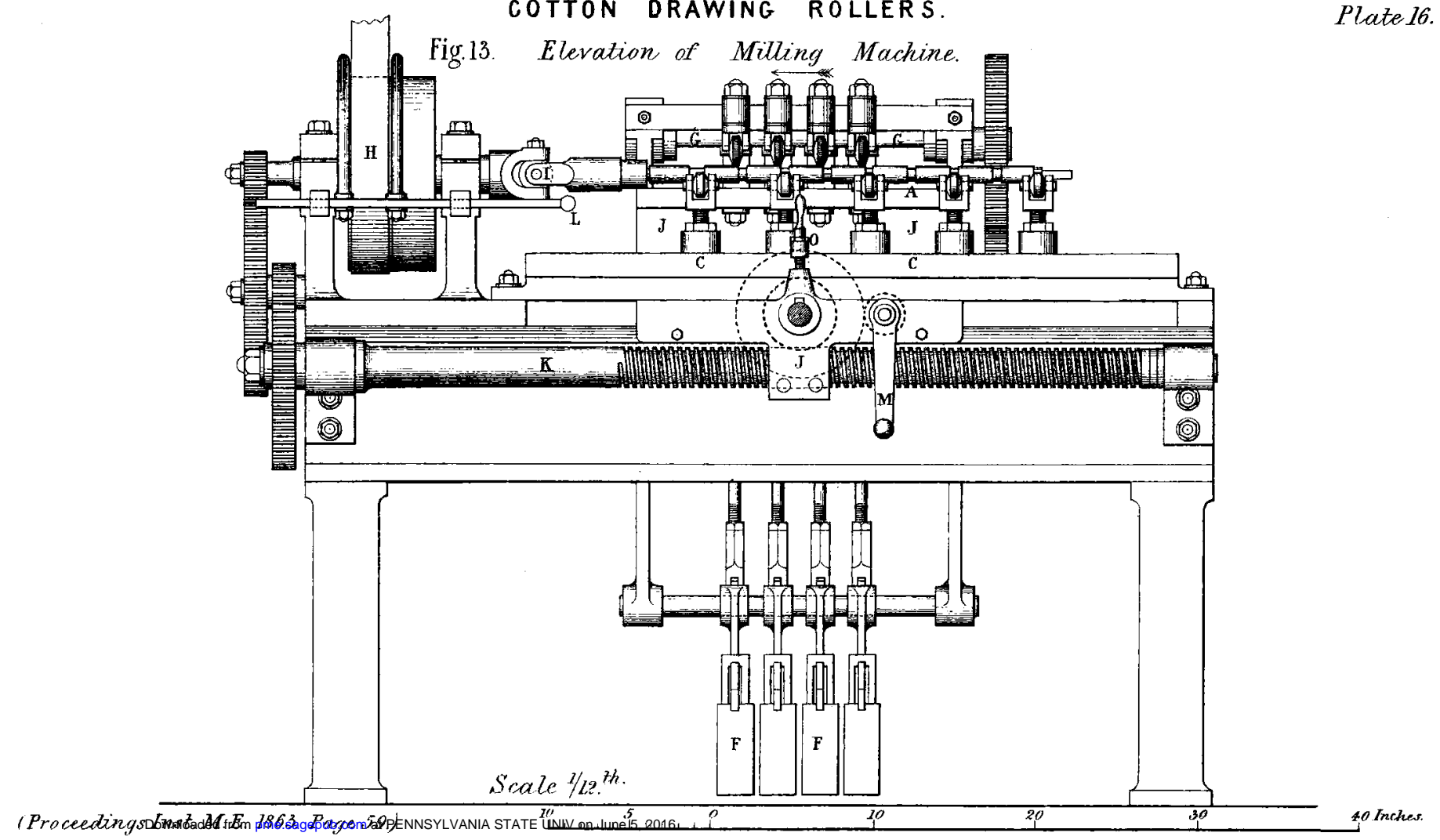


Fig.14. Transverse Section of Milling Machine.

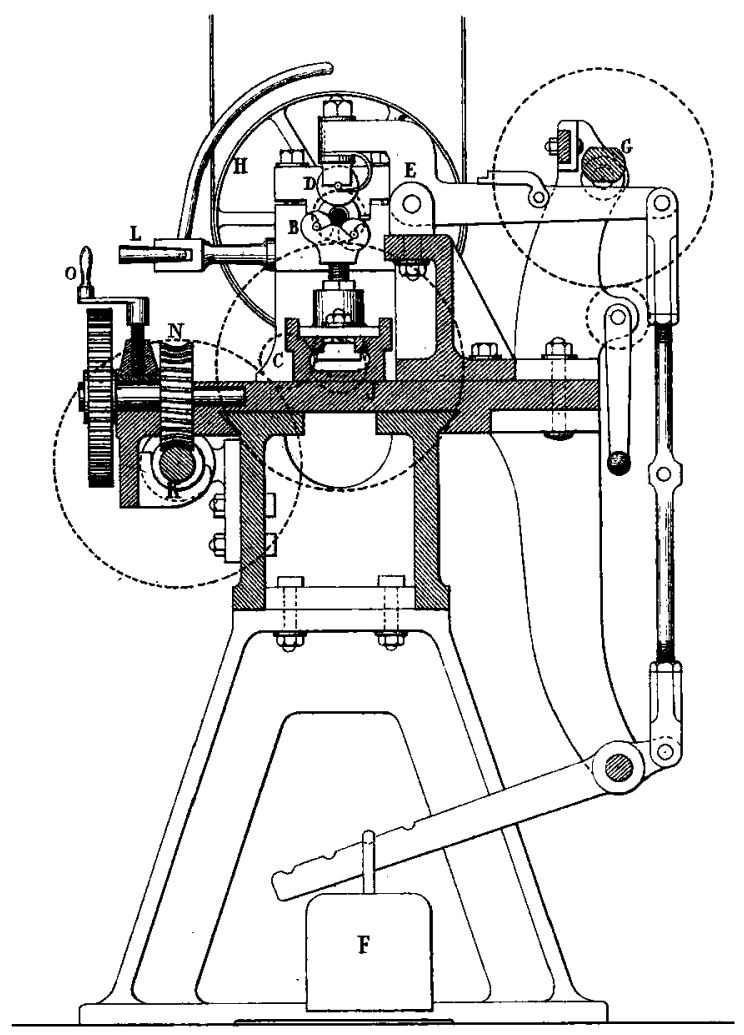

Fig. 15. Transverse Section

showing Mills lifted off Roller.

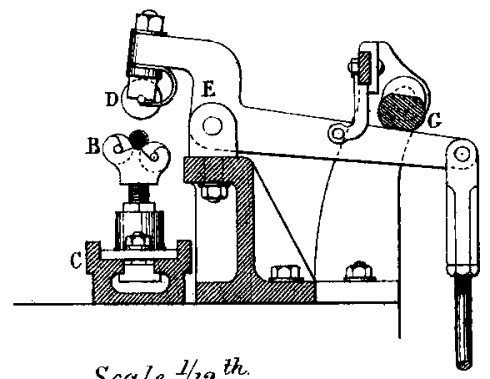

Scate $1 / 12^{\text {th }}$ 
COTTON DRAWING ROLLERS.

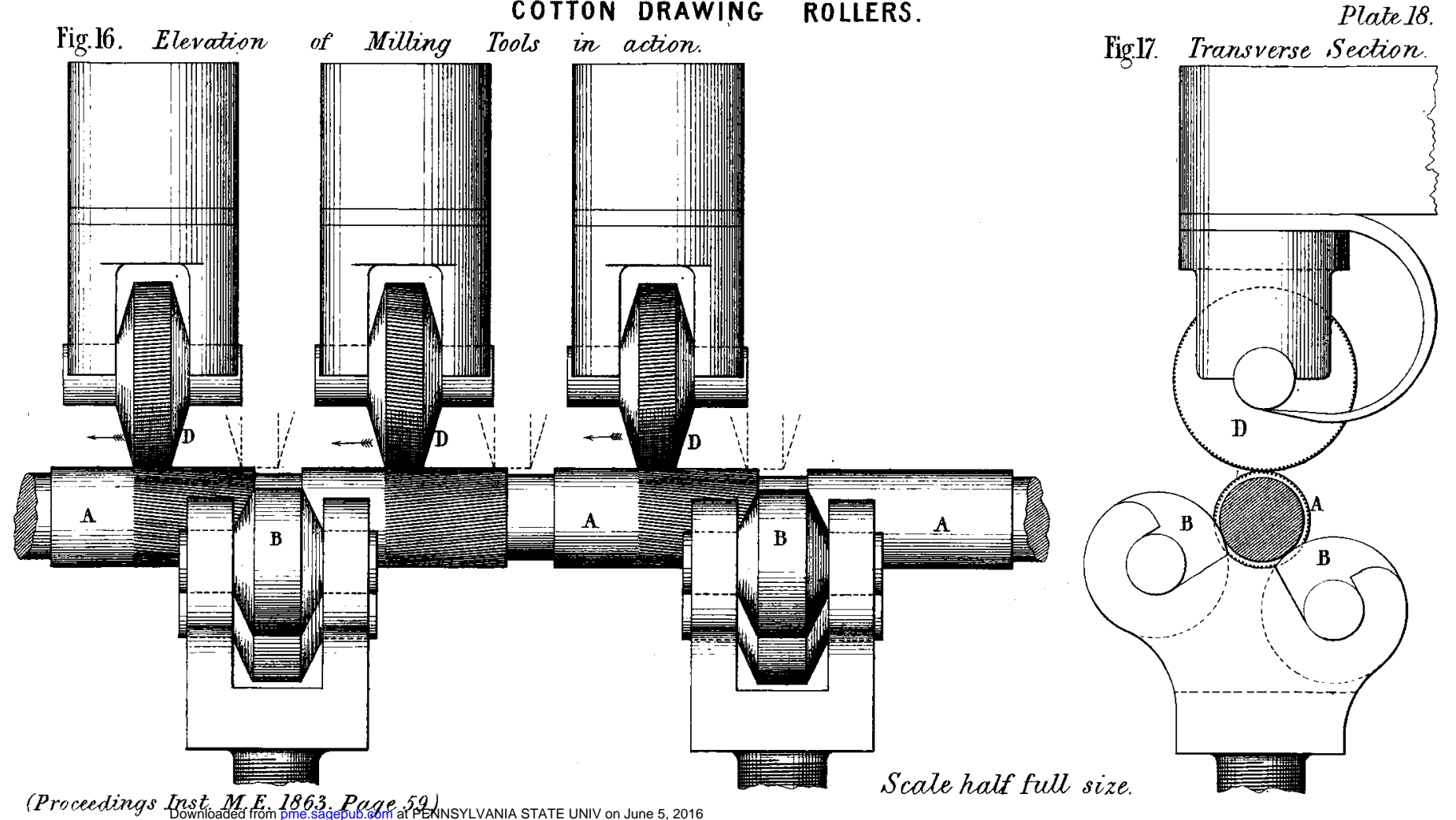


Fig. 18. Longitudinal Elevation of Drawing Roller, showing Coupling of successive lengths. Scale $1 / 6^{\text {th }}$.

至

Full size. Sections of Couplings of Drawing Rollers.

Fig. 19. Longitudinat Section of Bored Socket.

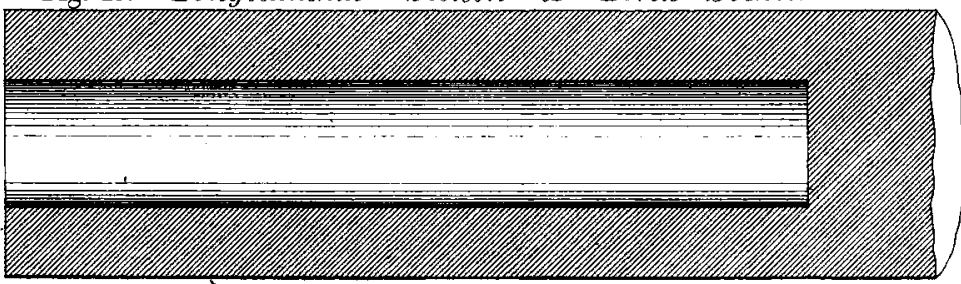

Fig. 20. Boring. Fig.21. First Punching. Fig.22. Second Punching.

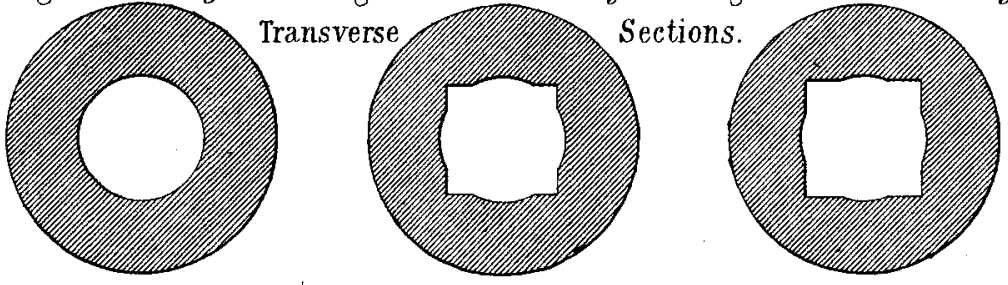

Fig.23. Longitudinal Section of finished Socket at XX (Fig24).

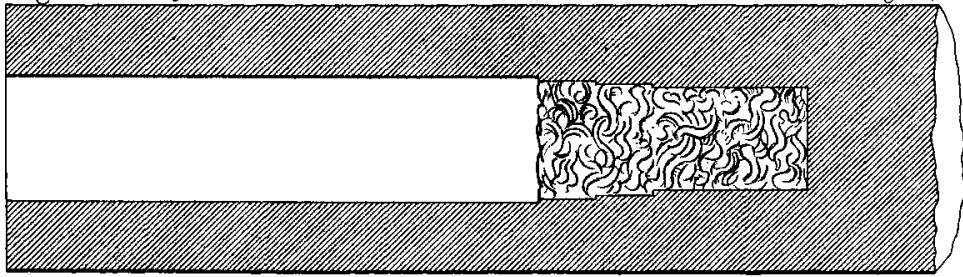

Fig.24. Finished socket.

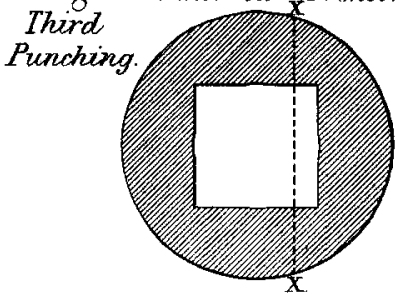

Fig.26. Side Elevation
Fig.25. Finished Spigot.

Transverse

Sections.

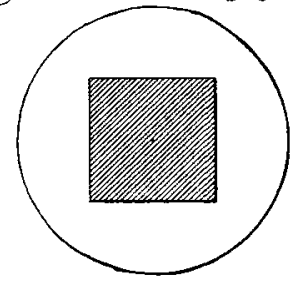

of finished spigot.

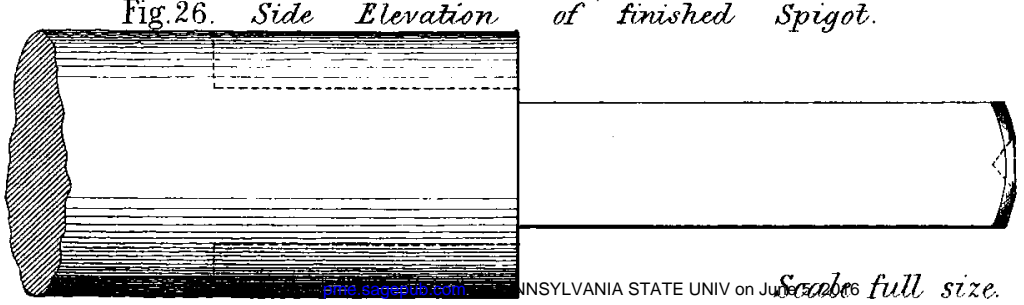

(Proceedings Inst. M.E. 1863. Page 59) 
COTTON DRAWING ROLLERS.

Plate20.

Fig.27. Drawing Rollers for Short fibred cotton. Full size.

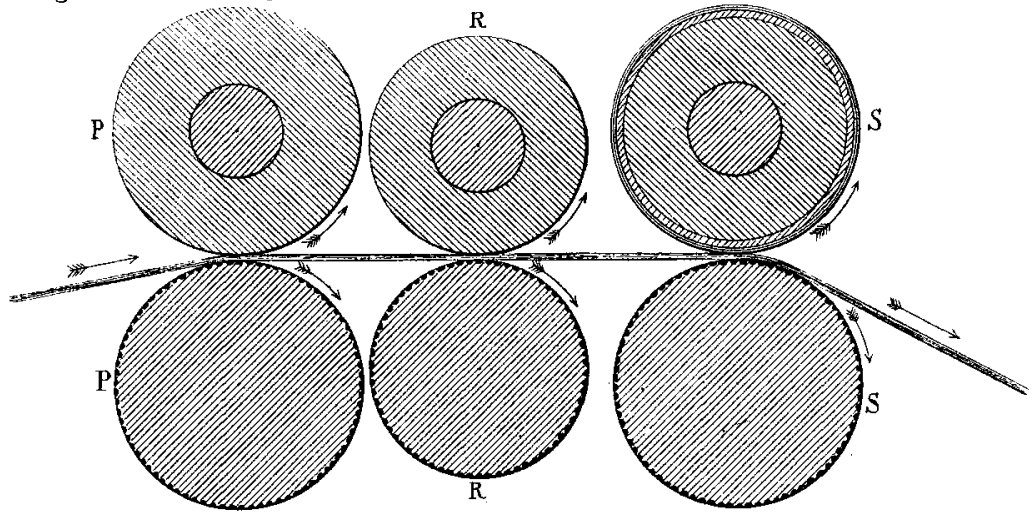

Fig. 28. Drawing Rollers for Long fibred colton. Full size.
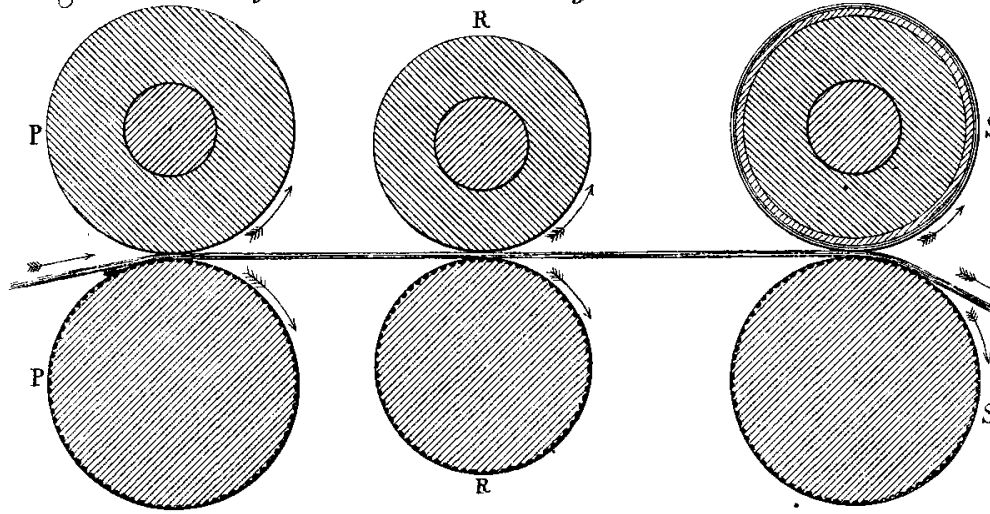

Fig.29. Diagram of Drawing Action.

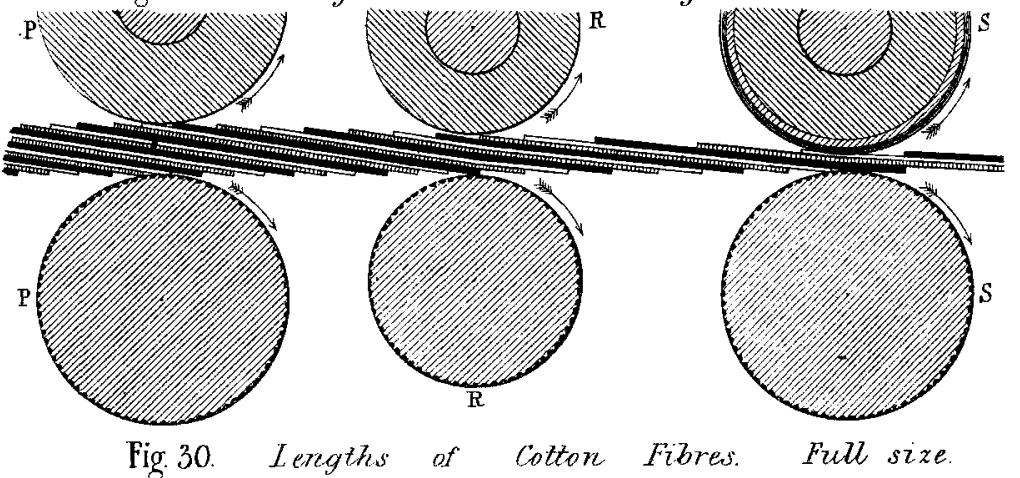

East Indian and Nantin

New Orteans ared Africust

Brazil and Eyyptian

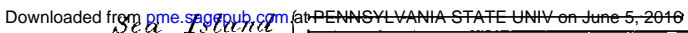

